\title{
Stroke mortality and its predictors in a Nigerian teaching hospital
}

Bertha Ekeh ${ }^{1}$, Adesola Ogunniyi², Emmanuel Isamade ${ }^{3}$, Udeme Ekrikpo ${ }^{1}$

1. University of Uyo Teaching Hospital, Internal Medicine

2. University College, Ibadan, Internal Medicine

3. Jos University Teaching Hospital, Internal Medicine

\section{Abstract}

Background: Stroke is the third leading cause of death worldwide. Stroke mortality has been noted to be higher in blacks in biracial studies. There have been few studies on stroke mortality and its predictors in Nigeria. This study examines mortality of stroke and its predictors in a Northern Nigerian teaching hospital.

Methods: This was a prospective study that was carried out at Jos University Teaching Hospital in Nigeria. One hundred and twenty stroke patients admitted into the medical wards within one year were assessed. Demographic data was recorded. Patients were examined and ancillary investigations were carried out. The deaths and predictors were recorded. Multivariate logistic regression was used to identify independent predictors of mortality.

Results: There were one hundred and twenty participants. Forty two (35\%), patients died. Most $(76.2 \%)$ deaths occurred within the first week. Predictors of mortality on univariate analysis were age $\geq 60$ years, male sex, loss of consciousness, high NIHSS score $(\geq 16)$, the presence of co-morbid conditions and presence of complications. On multivariate analysis, the predictors of mortality were the presence of co-morbid conditions, GCS $<10$ and high NIHSS score.

Conclusion: Stroke mortality was quite high in this study. Predictors of mortality were the indices of severity and the presence of co-morbid conditions.

Key Words: Co-morbid conditions, Level of consciousness, Mortality, National Institute of Health Stroke Scale (NIHSS score), Predictors, Stroke

\section{DOI: http://dx.doi.org/10.4314/ahs.v15i1.10}

\section{Introduction}

Stroke is one of the major public health problems in the world today ${ }^{1}$. It is the third leading cause of death worldwide after ischaemic heart disease and cancer ${ }^{2}$. Most of these stroke deaths are found in the developing countries. The deaths in these countries account for as much as $87 \%$ of all the stroke deaths ${ }^{3}$. This high death toll is even more in Sub Saharan Africa. Nigeria, the country where this study was carried out is a sub Saharan African country.

Epidemiological studies have identified risk factors for stroke for some years. These are classified into the

\section{Corresponding author:}

Bertha Ekeh

Department of Internal Medicine

UUTH, Uyo

E-mail address: berthacekeh@yahoo.com

234803 4018391, 2347052088085 non-modifiable and the modifiable risk factors. The non-modifiable risk factors are older age, male gender black race and family history. The commonest modifiable risk factor is hypertension. Other common risk factors are diabetes mellitus, central obesity, dyslipidaemias, cardiac disorders, vasculitis, heavy alcohol consumption and cigarette smoking 4 .

Additional well recognized risk factors are Sickle cell disease, oral contraceptives, vasculitic lesions and hypercoagulable states ${ }^{4}$. More recently, HIV and hyperhomocysteinaemia have been noted as novel risk factors for stroke ${ }^{5}$. The commonest risk factor in Nigeria remains hypertension ${ }^{6-8}$. Others notable risk factors in Nigeria are Diabetes mellitus ${ }^{6,7}$, central obesity ${ }^{6}$ previous stroke, cardiac disease and HIV

Blacks have been shown to have a large burden of stroke. Similarly, there are more severe strokes seen in the blacks than in other races. Mortality is also noted to be higher in blacks than other races. These differences in the burden, severity and mortality of stroke are seen even in biracial studies ${ }^{9,10}$. The case fatality rate of stroke in Africa is about 35\% but could be as low as $14.9 \%$ or as high as $77 \%$ when due to cerebral haemorrhage $^{11}$. In Nigeria, mortality rates are very high with a range of $21 \%-45 \% \%^{7,8,12-14}$ It is worthy of note that most of the dead patients in the Nigerian studies died within the acute phase ${ }^{7,12}$. Morbidity and mortality after stroke have been shown to arise from complications. Post-stroke complication is a leading cause of death accounting for $23-50 \%$ of total deaths in patients with ischaemic stroke. These include both medical and neurological complications ${ }^{15}$. Neurological complications frequently account for the worsening seen during the acute phase ${ }^{16}$.

Predictors of stroke mortality have been identified in different studies. Older age (age $>60$ years) has been shown to be a predictor of mortality ${ }^{17}$. This however was not the case in another study ${ }^{18}$. Likewise, the effect of sex on the outcome of stroke is varied. Some studies have noted that females have increased mortality and a lower one year survival ${ }^{19}$. While another study noted male sex to be a poor predictor ${ }^{18}$. There was yet another study that had an inconclusive result ${ }^{20}$.

Stroke mortality is an important outcome measure in stroke epidemiology studies and clinical trials. Data on stroke mortality therefore are critical for monitoring disease trends and planning public health interventions. The knowledge acquired in this study concerning the predictors of mortality will be of use in the management of patients more especially in the emergency services in acute stroke. This will lead to a reduction in stroke mortality and further disability.

Not much is known about mortality of stroke and its predictors in the northern part of Nigeria. This is because there have not been many studies in this part of the country on stroke mortality hence there is gap in the knowledge of the predictors of mortality. Management of stroke therefore is arbitrary at its worst. At best, it is based on studies with conclusions from other localities. Furthermore, the limited studies carried out in Nigeria (mostly the western part) were mostly retrospective and hence were hampered by incomplete data ${ }^{7,8,13}$. We therefore undertook this prospective study to examine the mortality of stroke in a city in Nigeria. The end points are the case fatality and the predictors of mortality. . The knowledge gained from this study will be of immense help in the in hospital care of stroke patient with a consequent reduction in stroke mortality. It will also be of use in health planning and promotion in my country Nigeria.

\section{Methods:}

This was a prospective study carried out in the Jos University Teaching Hospital (JUTH) in Nigeria to examine stroke mortality and its predictors. Jos is the capital of Plateau state in located in the North central Nigeria. This hospital serves as the referral centre in the state and also for nearby states in North central Nigeria. Being a teaching hospital, the hospital already had all the major clinical departments at the time of the study. The department of internal medicine where the study was carried out had several sub specialties/units at the time of the study. These are neurology, endocrinology, gastroenterology, cardiology, nephrology, respiratory, infectious disease. There was no stroke unit in the hospital hence all stroke patients were managed in the general medicine wards. Other special services in internal medicine services include dialysis services, HIV services, special tuberculosis care, endoscopy, and special diabetes care. There was a physiotherapy department which catered for patients who had need of rehabilitation like stroke survivors. The radiology department at the period of study had no available neuro imaging services. A Computed Tomography (CT) scan has since been installed. The study was carried out between January and December 2006.

The participants were one hundred and twenty patient who were admitted into the medical wards of the hospital with stroke. Stroke was defined as" rapidly developing signs of focal or global neurological disturbance of function leading to death or lasting longer than 24 hours with no other cause other than vascular”23.

The sample size was determined by the Beneth's formu$a^{24}: \mathrm{N}=\quad(\mathrm{Zi}-\mathrm{a})^{2}(\mathrm{p})(1-\mathrm{p})$

$\mathrm{N}$ is the minimum sample size while $\mathrm{P}$ is the best estimate of stroke prevalence from literature review as expressed as a fraction of 100.The community prevalence in Nigeria varies, but the earliest prevalence is $58 / 100,00011$ hence, 0.58 was used. $\mathrm{Zi}-\mathrm{a}$ is a constant as $95 \%$ confidence interval for two -tailed descriptive studies (1.96) while $\mathrm{d}$ is the absolute precision that is value (in percentage points) which in actual terms describes the maximum difference between the population rate and the sample rate that can be tolerated. Five 
$(5 \%)$ translating to 0.1 was adopted for this study. Minimal sample size was ninety three (93). However allowing for attrition a total of one hundred and twenty (120) patients were recruited for the study.

All consecutive patients with acute stroke who were more than 16 years and gave an informed consent were recruited for the study. The diagnosis was made clinically. Patients, who presented later than one week after the stroke, had transient ischaemic attack or head trauma were excluded. The 'WHO (World Health Organization) criteria' was used to sub type the stroke. Few patients, however, who could afford CT scan in the nearby centers, were confirmed by same to validate the diagnosis.

The history was taken from the patient and/or relatives in the language they understand. Components of the history included the demographic variables, history of stroke, past medical history, family and social history All the patients had their blood pressure measured using the mercury sphygmanometer available in the medical wards. Signs of longstanding hypertension and cardiac disease like displaced heaving apex beat, fourth heart sounds, loud $\mathrm{A}_{2}$ were noted. The Littman's stethoscope was used for auscultation.

The patients had a full neurological examination and the NIHSS score was recorded. The NIHSS stroke scale is an objective clinical tool used in the evaluation of stroke severity. The scale is designed to be simple and reliable. It comprises 15 items of neurologic examination. Neurological domains assessed are levels of consciousness, language, neglect, visual field loss, extra ocular movement, motor strength, ataxia, dysarthria and sensory loss. The lowest score for each parameter is 0 and the highest may be 2,3 or 4 . Persons with a low score have less severe strokes while those with a

\section{Table 1: Age and Sex Distribution of Patients with Stroke}

\begin{tabular}{|c|c|c|c|}
\hline AGE (Years) & MALE (\%) & FEMALE (\%) & TOTAL \\
\hline$<40$ & $11(57.9 \%)$ & $8(42.1 \%)$ & 19 \\
\hline $40-49$ & $11(55 \%)$ & $9(45 \%)$ & 20 \\
\hline 50-59 & $18(62.1 \%)$ & $11(37.9 \%)$ & 29 \\
\hline $60-69$ & $15(57.7 \%)$ & $11(42.3 \%)$ & 26 \\
\hline$>70$ & $19(73.1 \%)$ & $7(26.9 \%)$ & 26 \\
\hline TOTAL & $74(61.7 \%)$ & $46(38.3 \%)$ & 120 \\
\hline
\end{tabular}

The age range was $18-85$ years with a mean of $55 \pm 15.2$ tension while $78.3 \%$ had elevated blood pressure on adyears. The commonest risk factor was hypertension mission. Other common risk factors noted were central with as many as $70 \%$ having a prior diagnosis of hyper- obesity and diabetes mellitus (Table 2).

Table 2: All identified risk factors

\begin{tabular}{lllll}
\cline { 1 - 1 } Risk Factor & Male & Female & Total \\
\cline { 1 - 1 } Hypertension & $58(61.7 \%)$ & & $36(38.3 \%)$ & $94(78.3 \%)$ \\
Obesity & $43(58.9 \%)$ & & $30(41.1 \%)$ & $73(60.8 \%)$ \\
Diabetes Mellitus & $24(63.2 \%)$ & & $14(36.8 \%)$ & $38(36.7 \%)$ \\
Previous stroke & $20(76.9 \%)$ & & $6(23.1 \%)$ & $26(21.7 \%)$ \\
Cardiac disease & $2(40 \%)$ & & $3(60 \%)$ & $5(4.2 \%)$ \\
HIV/AIDS & $2(50 \%)$ & $2(50 \%)$ & $4(3.3 \%)$ \\
Sickle cell disease & $2(100 \%)$ & & $0(0 \%)$ & $2(1.7 \%)$ \\
Malignancy & $1(100 \%)$ & $0(0 \%)$ & $1(0.85 \%)$
\end{tabular}

Forty two (35\%) patients out of the one hundred and The level of consciousness was assessed with the Glastwenty died. Thirty two $(76.1 \%$ of the dead and $26.7 \%$ gow coma scale. The Glasgow coma score was $<10$ in of all the stroke patients) died within the first seven twenty nine (24.2\%) patients and $\geq 10$ in ninety one days. Eight more patients died by the end of 30 days $\quad(75.8 \%)$ patients. As much as twenty (69\%) of the twentaking the death toll to forty persons $(95.2 \%$ of the ty nine patients with a GCS $<10$ died while only nine dead and $33.3 \%$ of all the stroke patients). The last two $(31 \%)$ survived.

died by the end of the three months of observation.

Of the ninety one patients who had a GCS score $\geq 10$ Predictors of mortality on univariate analysis were age $\geq$ twenty two (24.1\%) died while as many as sixty nine 60 years, male sex, level of consciousness $<10$ and NI- $\quad(75.9 \%)$ survived $(\mathrm{p}<0.001)$.

HSS score $\geq 16$. There were fifty two patients who were more than 60 years. Twenty four $(46.2 \%)$ of these The NIHSS score was $<16$ (low) in sixty four $(53.3 \%)$ patients died and twenty eight (53.8\%) survived. Sixty patients and $\geq 16$ (high) in fifty six (46.7\%) patients. eight patients were less than 60years. Eighteen $(26.5 \%)$ Eight $(12.5 \%)$ of the sixty four patients with a low NIof these patients died while fifty $(73.5 \%)$ of them sur- HSS score died while fifty six $(87.5 \%)$ survived. Meanvived. $(\mathrm{p}=0.001)$.

while, thirty four $(60.7 \%)$ of the fifty six patients with high NIHSS score died while twenty two $(39.3 \%)$ surThirty one $(41.9 \%)$ out of the seventy four men died vived $(\mathrm{p}<0.000)$.

while forty three $(58.1 \%)$ survived. Eleven $(23.9 \%)$ of There were twenty patients who had other comorbid the forty six women died while thirty five (76.1\%) sur- conditions (Table 3). vived $(\mathrm{p}=0.047)$.

Fourteen $(70 \%)$ of them died and only six $(30 \%)$ sur-

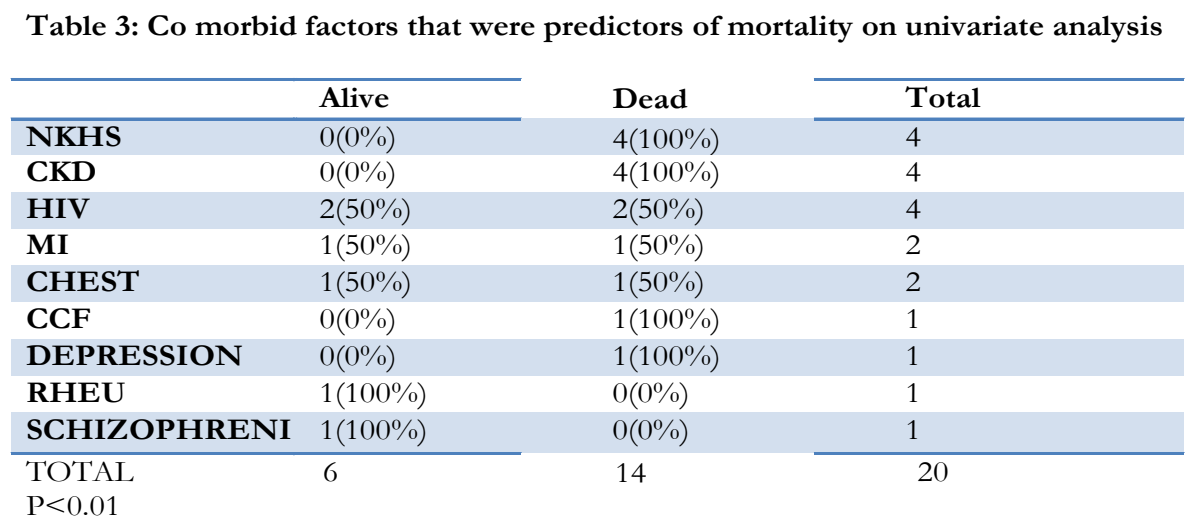

$\underset{\mathrm{P}<0.01}{\mathrm{~T}}$ 
vived. All the four $(100 \%)$ patients with non-ketotic fection died. The patient with congestive cardiac failure hyperglycaemic state died. All the four $(100 \%)$ patients and the patient with depression also died. One hunwith chronic kidney disease died. Two patients $(50 \%)$ dred others had no comorbidities. Twenty eight $(28 \%)$ out of the four patients with HIV/AIDS died. One died while the remaining seventy two (72\%) survived $(50 \%)$ of the two patients with myocardial infarction $(\mathrm{p}=0.001)$. Sixteen patients had different complications died. One $(50 \%)$ of the two patients with a chest in- (Table 4).

Table 4: Complications that were predictors of mortality on univariate analysis

\begin{tabular}{|c|c|c|c|}
\hline & Alive & Dead & Total \\
\hline Decubitus ulcer & $1(20 \%)$ & $4(80 \%)$ & 5 \\
\hline $\begin{array}{l}\text { Pulmonary } \\
\text { embolism }\end{array}$ & $0(0 \%)$ & $2(100 \%)$ & 2 \\
\hline Asp Pneumonitis & $0(0 \%)$ & $2(100 \%)$ & 2 \\
\hline UTI & $3(100 \%)$ & $0(0 \%)$ & 3 \\
\hline DVT & $1(100 \%)$ & $0(0 \%)$ & 1 \\
\hline Hypocalcaemia & $0(0 \%)$ & $1(100 \%)$ & 1 \\
\hline Dysphagia & $0(0 \%)$ & $1(100 \%)$ & 1 \\
\hline Burns & $0(0 \%)$ & $1(100 \%)$ & 1 \\
\hline Total & 5 & 11 & 16 \\
\hline
\end{tabular}

$P=0.003$

Eleven of these patients $(68.8 \%)$ died, while the remaining five $(31.2 \%)$ patients survived. Four $(80 \%)$ of the five patients who h $(100 \%)$ who had pulmonary embolism and two $(100 \%)$ others with aspiration pneumonitis also died. Other patients who died were the patients who had dysphagia, burns, and hypocalcaemia. None of the three patients who had urinary tract infection died. One hundred and

four patients did not develop any complications. Thirty one $(29.8 \%)$ of these patients died and seventy three (70.2\%) survived $(\mathrm{P}=0.005)$. Fever, fasting plasma glucose $\geq 10 \mathrm{mmols} / \mathrm{L}$ type of stroke, educational status and previous stroke were not predictors of mortality on univariate analysis. On multivariate analysis, the predictors of mortality were presence of comorbid factor GCS $<10$ and high NIHSS score (Table 5).

Table 5: Multivariate regression showing independ nt predictors of mortality in logistic stroke patients

\begin{tabular}{lll}
\hline & $\begin{array}{l}\text { Univariate analysis } \\
\text { Odds ratio }(95 \% \mathrm{CI}) \mathrm{p}-\text { value }\end{array}$ & $\begin{array}{l}\text { Multivariate analysis } \\
\text { Odds ratio }(95 \% \mathrm{CI}) \mathrm{p} \text { - value }\end{array}$ \\
\hline Age $\geq 60$ years & $2.38(1.11-5.12) 0.03$ & $0.86(0.20-3.66) 0.84$ \\
Male sex & $2.29(1.01-5.21) 0.047$ & $1.43(0.29-7.10) 0.66$ \\
\hline GCS $<10$ & $18.75(5.08-69.20)<0.001$ & $10.37(1.23-87.57) 0.03$ \\
NIHSS score $\geq 16$ & $7.98(3.13-20.28)<0.001$ & $6.22(1.08-35.82) 0.04$ \\
FPG $\geq 10$ mmols $/ \mathrm{L}$ & $2.32(0.79-6.74) 0.12$ & $2.58(0.42-16.08) 0.31$ \\
Presence of comorbidity & $6.00(2.10-17.17) 0.001$ & $7.44(1.29-42.71) 0.02$ \\
\hline Presence of complications & $5.18(1.66-16.15) 0.005$ & $3.35(0.59-2.98) 0.17$
\end{tabular}

Discussion:

We showed that stroke mortality was high in this study. There were a total of one hundred and twenty patients. Forty two of these patients died. This gave a case fatality rate of $35 \%$ which is quite high. It is important to note that most of these dead patients $32(26.7 \%)$ died within the first week. The first two weeks after the stroke comprise the acute phase. We therefore showed that the acute period is the critical period for patients with stroke. Interventions to reduce stroke mortality would be best targeted at the acute phase. Morbidity and mortality after stroke usually arise from complications. These include both medical and neurological complications. The neurological complications that have been described include brain edema, haemorrhagic transformation, seizures, delirium and recurrent stroke ${ }^{15}$.

These complications are said to be less frequent than the medical complications. They however occur earlie (within 48-72 hours after the stroke) than the medical complications and are known to affect outcomes with potential short-term and long-term consequences ${ }^{15}$. In our study however, it was unfortunate that the cause of death was not recorded in our dead patients. Thus the cause of death in our patients could not be determined but in some cases was presumed to be the complicating illness. Further studies will attempt to bridge this gap in knowledge. The prevention of these acute neurological complications will be paramount in reducing this high mortality. When this is not possible, early detection and proper management could be effective in reducing an adverse outcome.

The death toll in this study continued after the first week getting to forty $(95.2 \%$ of the dead and $33.3 \%$ of all the participants) by the end of thirty days. The corollary is that even after the acute period, the mortality continues albeit at a lower rate. The first factor contributing to the overall high mortality seen in our study will be that of absence of first rate and effective care. All the patients in this study had only supportive care which was not optimal. Stroke was an untreatable disease until recently. The vital intervention needed was made possible in 1995 when the National Institute of Neurological Disorders and stroke (NINDS) recombinant tissue plasminogen activator (rt-PA) stroke study group first reported that the early administration of rtPA benefited some carefully selected patients with acute ischaemic stroke ${ }^{25}$.Owing to this breakthrough study and the successful use of rt-PA, stroke has become a treatable disease. Thrombolytic drugs are commenced within three hours in acute ischemic stroke. Patients with haemorrhagic stroke may require neurosurgical interventions. These medications (thrombolytic agents) and neurosurgical procedures are not available in not ust in the study center but generally in our practice in Nigeria. These accounted immensely for sub optimal care to a large extent. The fear then is that this high mortality will continue if measures are not taken to provide optimal care for stroke patients. This high mortality we found in our study is comparable to what has been found in similar studies all over Africa where case fatality averages $35 \% 11$ and in Nigeria ${ }^{8,12,13}$

Another factor that contributed to the high mortality is the cost of care. The majority of the patients who participated in this study catered for all their own health bills. The per capita income in Nigeria is low. This makes even the available services and medications exor-

bitant for the common man. Only few of these patients (civil servants) have health insurance which took care of some of their bills. Widespread use of health insurance to lift the financial burden of care off our patients will be of great benefit to our patients. The absence of a dedicated stroke unit with the paucity of trained stroke experts in the study center and other centers in the country generally are other factors that further influenced the care received by the patients and eventual outcome.

Furthermore, stroke is generally believed to be a spiritual disease in the study city and in Nigeria as a whole. It therefore follows that some persons with stroke seek care elsewhere initially and if they subsequently present to the hospital, will come late. Some of these late

presenters already have complications which will lead to a further rise in mortality. There are also some cases where the patient is withdrawn from the hospital against medical advice. Some of these patients are taken to churches or traditional healers for treatment and are eventually lost to follow up. ${ }^{7}$ The high mortality recorded in this study may therefore just be the tip of the iceberg since. This ignorance has another facet apart from poor health seeking behaviour of our patients. Some of these patients were ignorant of the possible risk factors as they were unaware of their blood pressure measurement. What more, some patients with modifiable risk factors like hypertension and Diabetes mellitus are not compliant with their medications. Again the lack of necessary funds is a contributing factor to the poor compliance.

Finally, the inaccessibility to the health care facility especially in the rural areas was another factor in our study since a good number of our patients were not resident

African Health Sciences Vol 15 Issue 1, March 2015 
in Jos(the study center). This is mainly as a result of been discussed earlier.it therefore contributed remarkabad roads or unavailable means of transportation. Even bly to the severity of the stroke.

having after a stroke, there are no available emergen-

cy ambulance services for urgent transportation to the health care facility. There is therefore a continuum of poverty, poor health seeking behavior, poor and underdeveloped resources, noncompliance with medication, more severe strokes, lack of adequate hospital care with ensuing high mortality. In essence, proper and effective stroke care is very challenging in our practice. In the presence of these dire challenges, this high mortality rate may continue.

We also showed some independent predictors of mortality in our study. Factors found to be predictors on univariate analysis were age $\geq 60$ years, male sex, loss of consciousness, high NIHSS score $(\geq 16)$, presence of co-morbid factors and complications. Further analysis on multivariate analysis however established that high NIHSS score, the presence of comorbidity and GCS $<$ 10 were the predictors of mortality.

NIHSS score is a measure of stroke severity. It means that 'the higher the score, the more severe the stroke'. The inference is that in this study, our more severely affected patients were the ones that died. Reducing then severity of stroke will therefore be paramount in curtailing this high mortality. High NIHSS score has been shown to be the best predictor of outcome in stroke patients. High NIHSS score as a predictor of mortality, is consistent with what has been shown in another $\mathrm{Ni}_{-}$ gerian study ${ }^{14}$

Another predictor of mortality on multivariate analysis was the presence of comorbid conditions. The impact of these co-existing medical conditions on mortality was enormous. The common co morbid factors noted in this study were Non Ketotic hyperglycaemic state (NKHS), chronic kidney disease, HIV infection and myocardial infarction. All the patients who had either NKHS or CKD died. It is also noted that $50 \%$ of the patients who had either HIV, myocardial infarction or chest infection died. Comorbid conditions have been found to be predictors in some other studies ${ }^{26}$.

The level of consciousness was the final predictor of mortality. Patients who had a lower GCS were more likely to die. These were unarguably the more ill patients. Similar finding was noted in a previous Nigerian study. ${ }^{14}$. It is important to note that the GCS is a component of the NIHSS score whose significance has
The post stroke medical complications also contributed to the death toll seen in our study. It is interesting to note that $80 \%$ of those with decubitus ulcers all died. All the patients who developed pulmonary embolism and aspiration pneumonitis also died. Complication surprisingly were not predictors on multivariate analysis. This is mostly because there were milder complications like urinary tract infections where all the patients survived. The contribution however of the complication on the overall morbidity cannot be over emphasized.

Investigating the patients was the greatest challenge in this study. Computed tomography scan was not available in JUTH as at the time of the study. Patients howeve were sent to nearby centers namely Ahmadu Bello University Teaching Hospital, Zaria, Aminu Kano Teaching Hospital, Kano and the National Hospital, Abuja. This again was hampered by the funds and distance. Furthe more, two of the CT scan machines broke down in the course of the study. Recently, most teaching hospitals in Nigeria have a CT scan. Stroke patients are bette classified. Further studies will therefore examine the relationship between the type of stroke (CT diagnosed) and stroke mortality. Emphasis will be placed on the cause of death. The knowledge of the immediate cause of death and other contributory factors will greatly enhance our effective management of acute stroke patients.

\section{Conclusion}

Stroke mortality is very high in this study just like in most African studies. This high mortality is especially so during the acute phase. This high death toll is common in other Nigerian studies. The important predictors of mortality found in our study are the presence of comorbid conditions, NIHSS score and loss of consciousness. These are indices of severity of the disease.

\section{Recommendations}

Primary prevention measures with emphasis mainly on more aggressive control of risk factors should be of utmost importance. There should be public awareness campaigns to educate the public on the risk factors for stroke and their modifiable nature. The media, religious and community leaders could be used. This will reduce both the prevalence of stroke and the severity. There is a dire need for improved stroke care. This will include acute assessment, monitoring and investigation. Health workers that care for stroke patients need further train- ing especially in the prevention of complications. There is a burning need to establish stroke units in tertiar hospitals across the country for proper stroke care. Better funding of the health care system will go a long way to improve the quality of care. In the absence of these, this high mortality will regrettably continue.

\section{References}

1. American Heart Association: Heart and stroke update; Dallas, Texas 1998.

2. Feigin VL, Lawes CMM, Bennett DA, Barker -Collo SL, Pang V. Worldwide stroke incidence and early case fatality reported in 56 population based studies: A Systematic Review. Lancet Neurol 2009; 8:355-69 3. Saqui E. Stroke in sub Saharan Africa. Med Trop (Mars) 2007; 67: 596-600

4. Smith W S, Johnston S C, Easton J D. Cerebrovascular disease. In Kasper DL, Braunwald E, Fauci AS, Hauser SL, Longo DL, Jameson JL: Harrisons' Principles of Internal Medicine: 16th ED 2005

5. Report of WHO-Welcome Trust Meeting of experts: Secondary Prevention of Non-communicable diseases in low and middle income countries through community based and health service intentions. Geneva; World Health Organisation: 2001

6. Ekeh B C, Ogunniyi A O, Isamade E I. Stroke Ris factors among patients in a Nigerian Teaching Hospital. JMedtrop 2013:15(1); 33-6.

7. Njoku CH, Adeloju AB: Stroke in Sokoto, Nigeria: A five year retrospective study: Ann of Afr. Med 2004(2): 73-76.

8. Desalu OO, Wahab KW, Fawale B, Olarenwaju TO, Busari OA, Adekoya AO, Afolayan JO. A review of stroke admissions at a tertiary hospital in rural Southwestern Nigeria. Ann Afr Med 2011; 10: 80

9. Connor MD, Walker R, Mordi G, Warlow CP. Burden of stroke in black populations in Sub-Saharan Africa. Lancet Neurol: 2007; 6:269-275.

10. Kissela B, Schneider A, Kleindorfer D et al; Stroke in a biracial population: the excess burden of stroke among blacks; stroke 2004; 35: 42

11. Odusote K; Management of Stroke. Nig Med Pract 1996; 32:36-62.

12. Komolafe MA, Ogunlade O, Komolafe E.O: Stroke mortality in a teaching Hospital in South west Nigeria. Trop Doct 2007: 3; 186-188.6

13. Ogun S A. Acute stroke mortality at LUTH. Nig J Clin Pract 2003; 5:38-41.

14. Wahab K W, Okubadejo N U, Ojini F I, Danesi M A. Predictors of short-term intra- hospital case fatalit following first-ever acute ischaemic stroke in Nigerians. Coll Phy Surg Pak. 2008; 18:755-8.

15. Balami J S, Chen R, Grunwald I Q, Buchan A N. Neurological complications of acute ischaemic stroke. Lancet Neuro 2011; 10:357-71.

16. Weimar C, Mieck T, Buchthal J, et al for the German Stroke Study Collaboration. Neurological worsening during the acute phase of ischaemic stroke. Arch Neurol 2005; 62: 393-397.

17. Longo-Mbenza B, Tonduangu K, Muyeno K et al. Predictors of Stroke-associated Mortality in Africans. Revue d' epidemiologic et de santé publique 2000; 48(1):31

18. Anderson C S, Jamorozik K D, Stewart-Wayne E G. Predicting survival after stroke; Experience from the Perth community stroke study Clin Exp Neurol1992; 29:117-128.

19. Garbunsinski JN, Marianne A B, Van der sande MA Bartholomew EJ, Dramaix M D, Gave A, Coleman R et al: Stroke Presentation and Outcome in Developing countries: A prospective study in Gambia. Stroke 2005; 36: 138

20. Barret K M, Brott T G, Brown R D, Frankel M R, Worall B B, Silliman S L, Case L D, Rich S S, Mischia J F, for Ischaemic Stroke Genetics Study Group. Sex Differences in Stroke Severity, Symptoms and Deficit after First ever Ischaemic Stroke J of Stroke and Cerebrovasc Dis 2007; 16(1):34-39.

21. Asadollahi K, Beeching N, Gill G. Hyperglycaemia and Mortality J R Soc Med 2007; 100:503-507.

22. Adam HP, Davis PH, Leira EC, Chang KC, Bedixen B, Clarke WR, Woolson RF, and Hanson MF: Baseline

NIH stroke scale score strongly predicts outcome afte stroke: A report of the trial of org 10172 in acute stroke treatment (TOAST). Neurology 1999; 53:126.

23. Bulletin of the World Health Organization 2004; 82:503-508

24. Oyejide C O. Health Research Methods for Developing Country Scientists. ISBN 978-195-044-2 pp59-

25. The National Institute of Neurologic Disorders and Stroke rt-PA stroke study group: Tissue Plasminogen Activator for Acute Ischaemic Stroke: New Eng J Med 1995; 333: 1581-1587.

6. Saposnik G, Hill M D, O’Donell M, Fang J, Hachinski V, Kapral M K on behalf of the investigators of the Registry of Canadian Stroke Network for the Stroke Outcome Research Canada( SORCan) Working Group. Variables Associated with 7-day, 30-Day, and 1-year Fatality after Ischaemic stroke DOI: 10.1161/STROKEAHA.107.510362.

African Health Sciences Vol 15 Issue 1, March 2015 